\title{
Аденовирусный гепатит \\ с включениями - гидроперикардит кур и его профилактика
}

Бакулин В.А., доктор ветеринарных наук, профессор, зав. отделом вирусологии и опухолевых болезней птиц Всероссийский научно-исследовательский ветеринарный институт птицеводства (ВНИИВИП) - филиал ФНЦ «ВНИТИП» РАН

\begin{abstract}
Аннотащия: Аденовирусный гепатит с бключениями - гидроперикардит - широко распространенная болезнь кур. В современных схемах ее специфической профилактики предусматрибается применение инактивированных эмульсионных биопрепаратов. Представлены результаты эпизоотологического обследования птицехозяйств различных зон страны на аденовирусную инфекцию, сведения о регистрации абтором впервые в России данного заболевания, выделении, идентификаиии, изучении биологических свойств вируса-бозбудителя болезни, его паспортизации, а также основные теоретические аспекты технологии изготобления инактивированной эмульсионной бакцины и результаты изучения ее иммуногенных сбойсть 6 лабораторных и произбодственных условиях.
\end{abstract}

Ключебые слоба: аденовирусный гепатит с бключениями - гидроперикардит кур, диагностика, специфическая профилактика, инактивированная вакиина.

Введение. Аденовирусный гепатит с включениями - гидроперикардит кур (АДВГГ; синонимы: инклюзионный гепатит, гепатит с тельцами-включениями, гидроперикардит, гепатит-анемия-гидроперикардит, гидроперикардиальный синдром бройлеров, болезнь Ангара, болезнь Личи и др.) известен с 1963 г., после появления в США работы под названием «Острая катастрофа печени», посвященной «гепатиту с тельцамивключениями».

Болезнь обычно встречалась среди цыплят-бройлеров, реже у яичной птицы, в 4-8-недельном возрасте, иногда у 1-5-дневных цыплят, а также у кур-молодок и несушек. Гепатит с тельцамивключениями обнаруживался также у индеек, перепелов, фазанов, цесарок, уток, гусей. Смертность обычно в пределах 10-15\%, в экспериментальных условиях 60-100\%.
Доказана этиологическая роль аденовирусов 4, 5, 6 и 8 серотипов, но в экспериментальных условиях у СПФ-цыплят при парентеральном заражении заболевание мог вызвать аденовирус любого из 12 известных серотипов. В естественных условиях гепатит C включениями чаще протекал хронически или субклинически и из-за незначительности патологоанатомических изменений не всегда диагностировался.

До середины 80-х гг. XX века патологоанатомическое проявление болезни ограничивалось, в основном, незначительными изменениями в печени, которые часто расценивались как признак токсической дистрофии печени, гиповитаминозов, жирового гепатоза или гепатитов любого другого, но не аденовирусного происхождения. Периодически также регистрировались анемия, отек и геморрагии в подкожной клетчатке, нарушение свертываемости крови; встречалось скопление жидкости в брюшной полости, а чаще - в сердечной сорочке. Но «гидроперикардит», как и весь комплекс патологоанатомических изменений, встречался не всегда, и поэтому как признак болезни, несмотря на наличие литературных сведений, учитывался редко. Ситуация значительно изменилась с 1985 г., когда в ряде стран стало диагностироваться заболевание, особенно у бройлеров, с высокой смертностью птицы (от 25 до 70 и даже 100\%) и ярко выраженным на вскрытии «гидроперикардитом» (скоплением в сердечной сорочке от 5 до 20 мл жидкости соломенножелтого цвета или желеобразной массы). Было установлено, что это не новое заболевание, а тот же самый гепатит с тельцами-включениями, но с более интенсивным дополнительным патогене- 
тическим признаком и обусловленным нарушением кровообращения в сердечно-сосудистой системе. Подтверждено, что возбудитель болезни - аденовирусы птиц 1 группы, чаще 4 серотипа.

Для специфической профилактики АДВГГ в отечественной и зарубежной практике применяются инактивированные вакцины. Цыплят-бройлеров вакцинируют однократно в 10-17-дневном возрасте, внутримышечно или подкожно. Ремонтный молодняк и взрослых кур вакцинируют дважды: в 10-17 дней и затем при переводе в продуктивное стадо, в удвоенной дозе, не позднее чем за 30 дней до начала яйцекладки. В некоторых хозяйствах ремонтный молодняк, предназначенный для формирования родительских стад, в раннем возрасте вакцинируют дважды с 2-недельным интервалом, а затем третий раз в удвоенной дозе при переводе [1-3,5-7].

Материал и методика исследований. Эпизоотологическое обследование птицеводческих хозяйств на наличие АДВГГ проводилось по общепринятой методике. Аденовирус из патологического материала, полученного в неблагополучных по этой инфекции популяций кур, выделяли на восприимчивых цыплятах и эмбрионах кур.

Серологические исследования на выявление антигена в патологическом материале и антител в сыворотке крови проводились в реакции диффузионной преципитации в агаровом геле (РДП) и реакции нейтрализации на эмбрионах кур (РН). При постановке РДП использовали сыворотку крови, положительную к вирусу АДВГг.
Среди наиболее технологичных и эффрективных схем гипериммунизации цыплят для получения высокоактивных специфических сывороток как 1 серотипа (штамм Фелпс), так и 4 серотипа (штамм «Т-12») наиболее оптимальными оказались две следующие схемы иммунизации, позволяющие получить сыворотки с активностью в РДП 1:32 и выше. Схема № 1: парентеральное введение живого вируса, через 21-28 дней одно- или двукратная иммунизация инактивированным вирусом в эмульсионной форме. Схема №2: парентеральное введение инактивированного вируса (только антигена), через 21-28 дней одно- или двукратная иммунизация инактивированным вирусом в эмульсионной форме.

Гистологически исследовали печень, селезенку, поджелудочную железу. Материал фиксировали в 10\% растворе формалина или 96\% этиловом спирте, заливали в формалин, готовили парафиновые срезы, которые окрашивали гематоксилином и эозином.

Электронно-микроскопические исследования выполнялись по общепринятым методикам. Вируссодержащий материал негативно контрастировали 4\% раствором фосфорновольфрамовой кислоты по Нермуту и исследовали с помощью электронного микроскопа Tesla BS 540 и JEM 100B при увеличении 1,8 × $10^{5}$ (рис. 1).

За период с 1987 по 2020 гг. проведены эпизоотологические обследования и последующие лабораторно-диагностические исследования на наличие аденовирусной инфекции материала из 19 птицеводческих хозяйств Урала, Сибири, Дальнего Востока, Поволжья, Центральной зоны России, Красно-

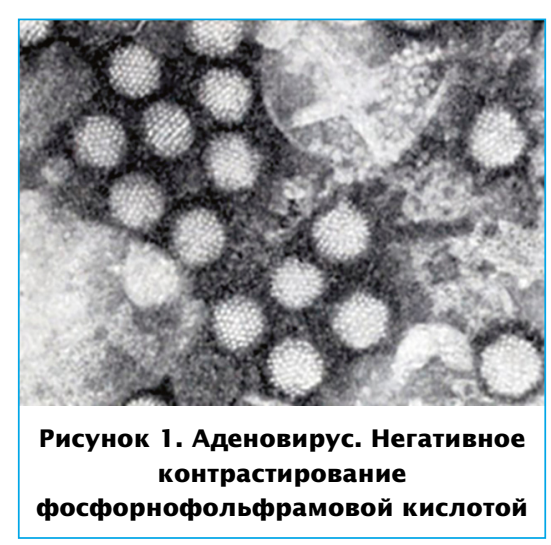

дарского и Ставропольского краев, Республик Карелия, Дагестан, Адыгея, Ленинградской, Новгородской и Московской областей.

После сравнительных исследований иммунобиологических свойств и изучения патогенеза выделенных изолятов вируса АДВГГ для разработки вакцины был выбран штамм «Т-12», который после всестороннего изучения был паспортизирован и депонирован в Государственной коллекции вирусов во ВНИИ вирусологии им. Д. И. Ивановского.

Штамм «Т-12» культивировали в организме цыплят мясных и яичных кроссов, с последующим использованием в качестве вируссодержащего материала печень. Вирус с активностью 2,5-2,75 lg ЛД мышечно цыплятам в дозе 0,3 мл и наблюдали в течение 7 суток. Активность полученного материала проверяли в РДП.

Для приготовления суспензии вируса АДВГГ вируссодержащий материал гомогенизировали в течение 10-30 мин в коллоидной мельнице в смеси с ФБР до получения 10\% суспензии. Затем суспензию трижды замораживали и оттаивали, и центрифугировали при 5000 об./мин в течение 15 мин.

Для удаления балластных примесей, в т. ч. белков из органо-тка- 
невого вируссодержащего материала, наиболее успешным было использование хлороформа, с последующим низкоскоростным центрифугированием. Очистку суспензии вируссодержащего материала проводили хлороформом (1-5\%), с последующим центрифугированием в течение 15 мин при 3000 об./мин.

Вирус инактивировали теотропином и димером аминоэтилэтиленимина $(0,05-0,4 \%)$ в течение 24-48 ч в соответствии с «Методическими указаниями по отбору, испытаниям и оценке антивирусных химиопрепаратов» (Москва, 1984) при температуре от 28 до $37^{\circ} \mathrm{C}$. Полноту инактивации аденовируса определяли методом 2-3-кратных «слепых» пассажей на 10-20-суточных цыплятах.

Экспериментальные серии жидкой инактивированной вакцины нарабатывали с использованием штамма «Т-12», который накапливали на восприимчивых цыплятах, инактивировали с помощью теотропина («А 24»), в качестве масляной эмульсии использовали инфузолипол.

Физические свойства инактивированных эмульгированных вакцин, в т.ч. стабильность эмульсии, определяли центрифугированием при 3000 об./мин в течение 30 мин.; кинематическую вязкость определяли на вискозиметре ВПЖ-2 (Россия) по методике, изложенной в паспорте прибора, и выражали в мм²$^{2}$ с.

Определение иммуногенной активности инактивированной вакцины (ИМД 50 /мл) определяли объемным методом путем введения разведений препарата $(1: 3$, $1: 9,1: 27$ и 1:81) 10-20-суточным цыплятам яичных кроссов, которых через 21 сут. после привив- ки заражали вирусом АДВГГ. Проверку учитывали, если из 10 контрольных цыплят заболевало не менее 6. ИмД формуле Кербера-Ашмарина: Ig ИмД $_{50 / \text { мл }}=\lg Д-\lg \mathrm{Kx}(£ L i-0,5)$. ПД $_{50}$ рассчитывали путем деления прививной дозы на значение Им ${ }_{50}$.

Статистическая обработка результатов проводилась с использованием общепринятых способов статистической обработки экспериментально полученных выборок варьирующих переменных. Определяли среднее значение выборки (М), стандартное отклонение (тх) и доверительный интервал средних. Корреляцию связанных переменных оценивали соответствующими коэффициентами. Значимость всех опубликованных величин была не ниже первого критериального порога ( $<<0,05)$.

Результаты исследований и их обсуждение. В процессе эпизоотологических обследований получены изоляты аденовирусов АДВГГ: «19/89» - в Челябинской области, «Т-12» - в Томской области, «Красноярский»- в Красноярском крае, «Карелия»- в Республике Карелия, «Тукаевский»в Татарстане, «ПрК-2001»- в Краснодарском крае.

Аденовирусная инфекция в острой, хронической и субклинической форме была зарегистрирована у птицы различных возрастов (от 1 - до 128-дневного возраста и у более старшей птицы) и кроссов. Болезнь протекала как самостоятельно, так и в ассоциации с инфекционной бурсальной болезнью (болезнью Гамборо), а также с реовирусной инфекцией, инфекционным бронхитом, колибактериозом и другими инфекционными болезнями, а также с асцитом незаразной этиологии.
При вспышках острой формы АДВГГ на птицеводческих предприятиях заболевали цыплята различных возрастов, из них гибло до 60-75\%. Доукомплектование родительского стада петухами и племенным яйцом от кур из птицефабрик, в которых отмечалось острое или подострое течение АДВГГ (вирус передается трансовариально и со спермой петухов), сопровождалось вспышками болезни с очень высокой смертностью цыплят 3-5-дневного и более старшего возраста.

Для постановки диагноза и выделения вируса проводили биопробу на серонегативных 12-суточных цыплятах. Материалом для заражения служила очищенная хлороформом 20\% суспензия печени спонтанно заболевших птиц из обследуемых хозяйств. Суспензию в объеме 0,3 мл вводили внутримышечно. При экспериментальном заражении птиц (биопробе) клинические признаки болезни проявлялись на 3-4 сутки у 60-85\% особей и были схожи с симптомами, наблюдаемыми при спонтанном течении болезни. На вскрытии характерные признаки отмечали в 70-90\% случаев. Одновременно, исследуя гомогенат печени спонтанно заболевших цыплят в РДП со специфической иммунной сывороткой, подтвердили наличие антигена вируса АДВГГ в исследуемых пробах. Антитела в РДП выявили в сыворотке крови птицы 2-, 90-, 231- и 347-суточного возраста, доставленной из вышеуказанных хозяйств.

Морфологические изменения в органах и тканях (рис. 2) при спонтанном и экспериментальном заражении цыплят АДВГГ в целом были сходными: гепатит с 

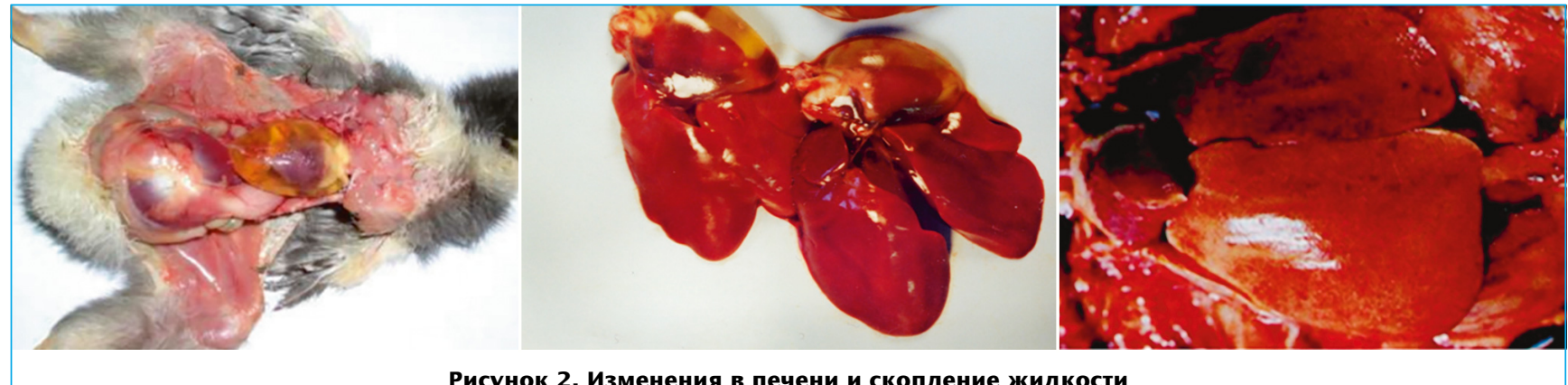

в перикардиальной полости («гидроперикардит») при остром течении АДВГГ

внутриядерными эозинофильными и базофильными тельцамивключениями (рис. 3); панкреатит с внутриядерными включениями в клетках железистой ткани; спленит с характерными включениями в ядрах ретикулярных клеток; нефрозонефрит; гипоплазия лимфоидных фолликулов фабрициевой сумки (у некоторых птиц в ретикулоэпителиальных клетках находили внутриядерные включения); гипоплазия тимуса и костного мозга; отек легких; неспецифический миокардит.

Впервые установлено, что при заражении цыплят штаммом АДВГГ «Т-12» происходит проникновение и репликация аденовирусов в иммунокомпетентных, в том числе в ретикулярных антигенпредставляющих клетках лимфоидных органов с последующей их деструкцией, что отрицательно сказывалось на устойчивости инфицированной аденовирусом птицы к заражению возбудителями других заразных болезней а также на формировании поствакцинального иммунитета, в том числе к ньюкаслской и инфекционной бурсальной болезни (ИББ).

При заражении эмбрионов кур отмечается отек, утолщение, помутнение и гиперемия хориоаллантоисной оболочки, иногда наличие в ней очагов некроза и кистозных разрастаний, отставание эмбрионов в развитии, с гиперемией и подкожными кровоизлияниями. Печень эмбрионов гиперемирована, с очагами некроза и кровоизлияниями. Максимальная смертность эмбрионов происходит на 4-5 день после заражения. При гистологических исследованиях в ядрах эктодермального эпителия хориоаллантоисной оболочки и гепатоцитов встречаются тельца-включения.

Вирусологическими (выделение вируса), серологическими (постановка РДП) и гистологическими исследованиями впервые доказано, что аденовирус штамма «Т-12» реплицируется в клетках железистой ткани поджелудочной железы, вызывает панкреатит и пагубно сказывается на цыплятах 1-20-дневного возраста с не сформированной окончательно эндокринной системой.

Электронная микроскопия показала наличие в вируссодержащем материале безоболочечных вирусных частиц с икосаэдрической структурой капсида, диаметром 70-80 нм, с шестью капсомерами на грани (рис. 1). Структура и размеры выявленных частиц были аналогичны структуре и размерам аденовирусов.

Микробиологическими исследованиями материала, содержащего вирус АДВГГ штамма «Т 12», подтверждали отсутствие в нем микоплазмам, бактерий, грибов и посторонних вирусов.

Штамм периодически проверялся на инфекционную активность. Проводили 10 последовательных пассажей на 10-суточных цыплятах, с определением показателя смертности и титра инфекционной активности. Вирус был высоковирулентен и вызывал после заражения гибель от 90 до $100 \%$ цыплят. Инфекционная активность штамма была не менее $3,58 \pm 0,20 \lg$ ЛД $_{50 / 02 \text { мл }}$.

Оценку иммуногенной активности штамма проводили в составе инактивированной вакцины, которую готовили из 10\% суспензии печени цыплят, полученной от 1, 5 и 10 пассажа.

В качестве адьюванта использовали инфузолипол, который обладает адъювантными и вируспротективными свойствами в сочетании с экологической чистотой и безвредностью. Препарат инфузолипол - это 10\% жировая эмульсия типа «масло в воде», получаемая методом гомогенизации под высоким давлением, представляет собой однородную жидкость молочно-белого цвета; состоит из растительного масла, лецитина, сорбита и воды. Он не токсичен при длительном введении, не антигенен, не обладает пирогенными свойствами. Инфузолипол апробирован во ВНИВИП 


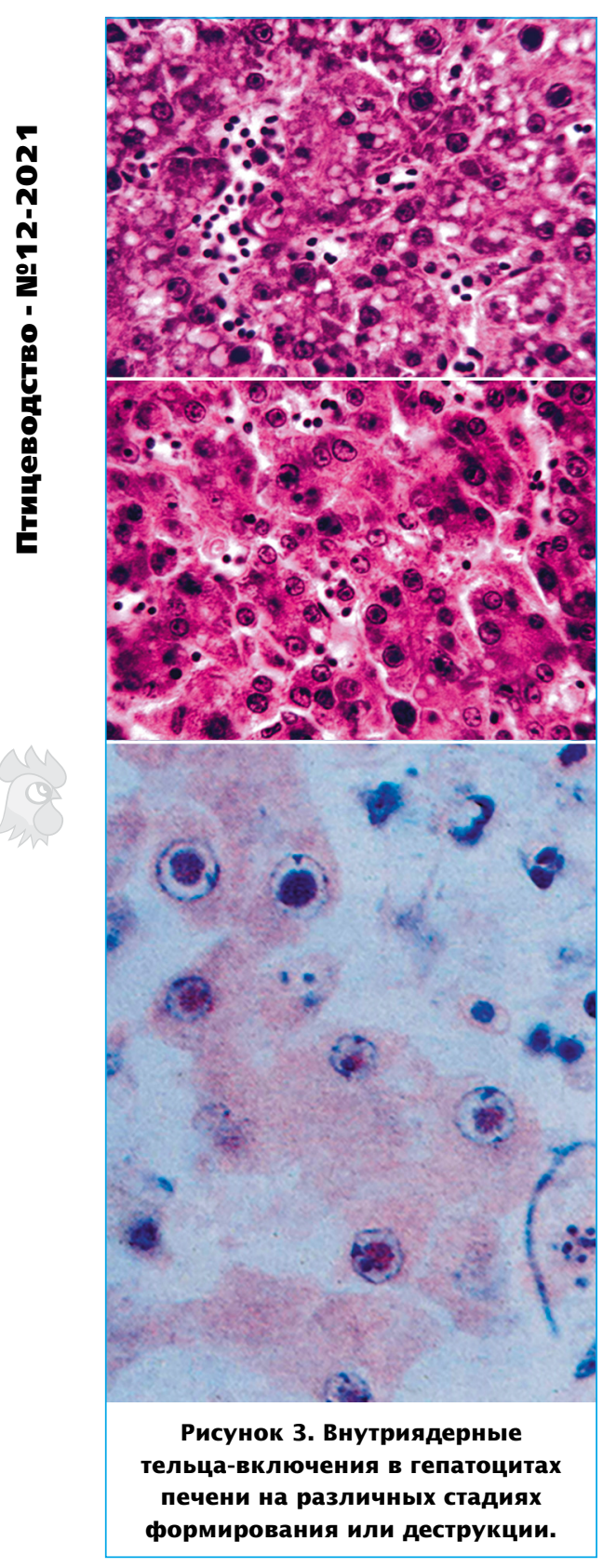

и использовался для разработки «Вакцины против аденовирусного гепатита с включениями - гидроперикардита кур жидкой инактивированной» (ТУ 9384-01400495674-04, от 20.07.04 г., патент на изобретение RU 2233175 от 27.07.2004 г.).

При лабораторных исследованиях установлено, что вакцина против АДВГГ жидкая инактивированная, примененная на 1-15-суточных цыплятах и птице более старшего возраста (по данным различных опытов, в том числе комиссионных), способна предохранять от гибели от 80 до 100\% иммунизированных цыплят после контрольного заражения патогенным штаммом, при смертности 80-100\% невакцинированных птиц [4-6]. В экспериментальных условиях, уже на 3-5, тем более на 7-10 сутки после вакцинации 80-100\% цыплят не погибает после контрольного внутримышечного заражения патогенным штаммом при смертности среди контрольных невакцинированных птиц 90-100\%. Вируспреципитирующие антитела в РДП выявляли в сыворотке крови у 80\% вакцинированных цыплят на 21 и у 100\% - на 28 сутки после иммунизации.

При апробации вакцины в производственных условиях ЗАО «Птицевод» Краснодарского края было установлено, что сохранность вакцинированных бройлеров выше на 14,9\% по сравнению с непривитыми цыплятами. Затем с положительным эффектом препарат был неоднократно испытан в различных птицеводческих хозяйствах страны. Производственные испытания вакцины против АДВГг проведены на птицефабрике «Щербиновская», где наблюдалось субклиническое, с периодическими обострениями, течение болезни. Данные, полученные при испытании вакцины даже при слабовыраженном проявлении аденовирусной инфекции, показали, что препарат в вакцинированной группе птицы обеспечивает более высокую (на 5,1\%) общую сохранность цыплят-бройлеров и снижает количество павших с признаками аденовирусной инфекции (на 19,5\% от общего числа погибших). Вакцина улучшает многие зоотехнические показатели, что за период выращивания цыплят бройлеров позволяет получить экономический эффект на 1000 вакцинированных цыплят в размере 1866,0 руб., или 28,58 руб. на 1 руб. дополнительных затрат. Вакцина безвредна для цыплят, иммуногена и может быть рекомендована для применения в промышленном птицеводстве.

При научно-производственном испытании инактивированной вакцины на птицефабрике «Концерн Великий Новгород» Новгородской области, неблагополучной по АДВГГ, препарат вводили внутримышечно, в область бедра, в объеме 0,5 мл/ гол. молодняку кросса Росс-308 15-суточного возраста. Контрольная группа была сформирована из непривитой птицы. Помимо вакцинации, в хозяйстве с момента регистрации болезни осуществили комплекс ветеринарно-санитарных мероприятий, а в рационы дополнительно ввели витамины, микроэлементы, аминокислоты и антиоксиданты. Результаты производственных испытаний свидетельствуют о том, что при иммунизации инактивированной вакциной из штамма «Т 12»у бройлеров повышались сохранность (на 8,9\%), среднесуточный прирост живой массы (на 4,7 г), средняя убойная живая масса (на 186 г), а также снижались затраты корма на единицу продукции (на 0,21 кг). Существенно (до 2,0\%) уменьшилось количество павшей птицы с характерными для АВДГг признаками поражения печени, при смертности невакцинированных цыплят с признаками АДВГг 42,0\% от числа павших. 
Случаев проявления какой-либо патологии у привитой птицы, в т.ч. в месте введения вакцины, не отмечалось. У вакцинированных против АДВГГ цыплят отмечали более высокий уровень специфических антител к возбудителям ньюкаслской болезни и ИББ, а количество павших от колибактериоза особей, особенно на завершающих этапах откорма, было меньше. При проведении бактериологических исследований печени и содержимого кишечника у невакцинированной птицы (контрольная группа) преобладала патогенная микрофрлора (E. coli серотипа 015 и S. enteritidis).

Выводы. Впервые в стране, на птицефабрике «Сосновская» Челябинской области, за счет комплексных исследований, в т.ч. выделении и идентификации аденовируса и постановки биопробы, установлен АДВГГ. Этиологическим агентом АДВГг является аденовирус, родственный референтному штамму серотипа FAdV4, рода Aviadenovirus.

Разработана и испытана в лабораторных и производственных условиях инактивированная эмульсионная вакцины против АДВГГ на основе штамма «Т 12», репродуцированного в организме восприимчивых птиц. Вакцина безвредна, антигенно активна, высокоиммуногенна при разных способах парентерального введения и сохраняет свои иммунобиологические свойства при длительном хранении при температуре от 2 до $8^{\circ} \mathrm{C}$ (срок наблюдения - до 12 месяцев). Напряженный иммунитет у привитых птиц сохраняется в течение 6 месяцев.

Вакцина способна предохранять от гибели от 90 до 100\% иммунизированных цыплят после контрольного заражения патогенным штаммом, при смертности 80-100\% невакцинированных птиц. Такая устойчивость начинает проявляться уже на 3-5 сутки после вакцинации.

Цыплята, полученные от кур, привитых инактивированной вакциной против АДВГГ, имеют пассивный иммунитет против этой болезни, который сохраняется до 12-14-суточного возраста.

\section{Литература}

1. Алиев А.С., Сираждинов Р.С., Никитина Н.В. Инфекционный гидроперикардит цыплят-бройлеров. - СПб, 2000. - 20 c.
2. Бакулин В.А., Радчук Л.А., Алиев А.С. [и др.] Патоморфология спонтанного проявления аденовирусного гепатита с тельцами-включениями у цыплят // Передовой научно-производственный опыт в птицеводстве: Экспресс-инф. - 1989. - №3. - С. 31-33. 3. Бакулин В.А. Иммунодефициты птиц. - СПб.: Свет, 2019. - 308 с.

4. Бакулин В.А., Коровин Р.Н. Штамм «Т-12» вируса аденовирусного гепатита с включениями - гидроперикардита кур (АДВГГ) для производства диагностикумов и вакцин и экспериментального изучения болезни. - Патент RU 2277584. - 2006.

5. Борисов В.В. Вирусный синдром гидроперикардита кур // Птица и птицепродукты. - 2003.- №1. - С. 29-32.

6. Крон Н.В. Иммунобиологические свойства вируса инфекционного гидроперикардита птиц. - СПб., 2003. $19 \mathrm{c}$.

7. Ahmad I., Afzal M., Malik M.J., Hussan Z., Hanif W. Studies on the disease pattern and aetiology of hydropericardium syndrome (Angara disease) in broiler chickens in Pakistan // Pakistan J. Agric. Res. - 1998. - V. 10. - P.195-199.

\section{Для контакта с автором:}

\section{Бакулин}

Валерий Александрович

E-mail: bakulinva@bk.ru

\title{
Chicken Adenoviral Hepatitis-Hydropericardium Syndrome: Diagnostics and Specific Prophylaxis
}

\author{
Bakulin V.A. \\ Federal Scientific Center "All-Russian Research and Technological Institute of Poultry" \\ of Russian Academy of Sciences
}

Summary: Chicken adenoviral inclusive hepatitis-hydropericardium syndrome (Angara disease) is presently a wide-spread disease requiring the specific prophylaxis with the use of inactivated vaccines. The results of the monitoring of the disease on poultry farms of different regions of Russia; identification, investigation and registration of the causative adenovirus; the technology of the inactivated oily emulsified vaccine and the results of the testing of the vaccine in laboratory conditions and on different Russian poultry farms are presented.

Keywords: chicken adenoviral inclusive hepatitis-hydropericarditis, diagnostics, specific prophylaxis, inactivated vaccine. 